\title{
Ensaios de penetração de Salmonella Enteritidis em ovos de galinha com diferentes qualidades de casca, submetidos ou não a lavagem industrial e a duas temperaturas de armazenagem
}

\author{
[Penetration of Salmonella Enteritidis in chicken eggs, comparing different shell quality, \\ industrial washing and temperature of storage] \\ A.T. Pinto ${ }^{1}$, E.N. Silva ${ }^{2}$ \\ ${ }^{1}$ Universidade Federal do Rio Grande do Sul \\ Av Bento Gonçalves 9090 \\ 91540-000 - Porto Alegre, RS \\ ${ }^{2}$ BIOCAMP Laboratórios - Campinas, SP
}

\begin{abstract}
RESUMO
Estudou-se o comportamento da Salmonella Enteritidis quando em contato com a superfície de ovos de consumo, classificados de acordo com a qualidade da casca ou com tratamentos (lavados ou não), usando fezes de aves como veículo de contaminação, e armazenados a $8^{\circ} \mathrm{C}$ e $70 \%$ de umidade relativa ou a $30^{\circ} \mathrm{C}$ e $90 \%$ de umidade relativa. A $8^{\circ} \mathrm{C}$, o microrganismo permaneceu viável na superfície dos ovos, ao longo do tempo, enquanto a $30^{\circ} \mathrm{C}$ foi possível identificar a sua inibição e até sua eliminação da superfície. A contaminação do conteúdo de ovos com defeito de casca foi mais frequente quando os ovos foram submetidos a temperaturas inadequadas de armazenagem $\left(30^{\circ} \mathrm{C}\right)$.
\end{abstract}

Palavras-chave: ovo, qualidade da casca, Salmonella Enteritidis, conservação de ovos

\begin{abstract}
Salmonella Enteriditis behavior was studied when present on the surface of consume eggs, classified according to the shell quality or treatments (washed or not). Stools of fowls were used as a vehicle for contamination. The eggs were stored at $8{ }^{\circ} \mathrm{C}$ and $70 \%$ relative humidity or at $30^{\circ} \mathrm{C}$ and $90 \%$ of relative humidity. At $8^{\circ} \mathrm{C}$, the microorganism stayed viable on the surface of the eggs throughout the study, while at $30^{\circ} \mathrm{C}$ it was inhibited and eliminated from the egg shell. The contamination of content of the eggs with shell defect was more frequent when they were submitted to inappropriate temperatures of storage $\left(30^{\circ} \mathrm{C}\right)$.
\end{abstract}

Keywords: eggs, shell quality, Salmonella Enteritidis, eggs conservation

\section{INTRODUÇ̃̃O}

Ovos de galinha são apontados como principal responsável pela salmonelose em seres humanos (Humphrey, 1994; Peresi et al., 1998; Latimer et al., 2000).

Os estudos da invasão do conteúdo, sobrevivência e multiplicação de salmonelas em ovos utilizam metodologias que conferem elevada contaminação inicial, incriminando-os como importantes veiculadores da doença.
Entretanto, quando são realizados estudos epidemiológicos, observa-se que apenas uma pequena parcela dos ovos produzidos contém o microrganismo na superfície ou em seu interior (Summers, 2002).

Salmonella Enteritidis (SE) é frequentemente isolada em produtos avícolas em geral, em aves de postura e em granjas de poedeiras no Brasil (Silva e Bosquiroli, 1996; Tavechio et al., 2002; Gama et al., 2003), sendo o principal patógeno associado a salmoneloses veiculadas por ovos.

Recebido em 10 de outubro de 2008

Aceito em 28 de agosto de 2009

E-mail: andrea.troller@ufrgs.br 
Oliveira e Silva (2000) encontraram 9,6\% das superfícies de ovos e 3,2\% das gemas de ovos de consumo disponíveis no mercado contaminados por salmonelas, enquanto Cardoso et al. (2002) não encontraram o microrganismo em estudo semelhante.

A casca é a primeira e mais importante barreira à penetração de microrganismos em ovos. As principais fontes de contaminação da superfície de ovos, além da cloaca, no momento da postura, são poeira, terra e fezes (Board e Tranter, 1994).

A contaminação interna de ovos, a partir da contaminação ambiental, como material de cama de poedeiras foi comprovada e, provavelmente, é dependente da qualidade da casca (Oliveira e Silva, 2000). O ambiente de criação de poedeiras e de produção de ovos pode ser altamente contaminado por diversos sorotipos de Salmonella, incluindo SE (Henzler et al., 1998; Davies et al., 2003; Gama et al., 2003). Há relação direta entre a presença do microrganismo no ambiente e a ocorrência de ovos contaminados (Henzler et al., 1998).

Os riscos da infecção humana estão associados ao comércio de ovos com casca defeituosa, fina, porosa ou rachada, ou sujos com matéria orgânica, à falha ou inexistência de refrigeração ao longo da produção e comércio e ao equivocado manuseio do produto, ainda nos locais de produção e classificação (Tood, 1996).

Ovos podem veicular o microrganismo após a lavagem industrial (Summers, 2002) e se contaminar após esse procedimento. Em vista da variabilidade de pontos críticos de contaminação, o objetivo foi estudar a penetração de Salmonella Enteritidis em ovos de galinha com casa íntegra ou com defeitos e em ovos íntegros que foram submetidos ou não à lavagem industrial ou a diferentes condições de armazenagem tais como $8^{\circ} \mathrm{C}$ e $70 \%$ de umidade relativa ou a $30^{\circ} \mathrm{C}$ e $90 \%$ de umidade relativa (UR).

\section{MATERIAL E MÉTODOS}

Foram utilizados ovos com peso de $60,0 \pm 3,0 \mathrm{~g}$, oriundos de um mesmo lote de poedeiras da linhagem HySex White, com idades entre 35 e 50 semanas.
A determinação da qualidade da casca foi feita por inspeção visual e ovoscopia. Ovos classificados como sem defeitos de casca foram aqueles que não apresentaram defeitos visíveis. Ovos com defeitos de casca foram aqueles que apresentaram defeitos não desclassificatórios, como casca fina ou porosa, ou pequenas rachaduras sem rompimento das membranas internas. Como padrão de classificação, utilizaram-se as fotografias disponíveis em Solomon (1991) e no Egg quality guide ${ }^{1}$. Os ovos selecionados foram dispostos em bandejas para transporte ao laboratório.

Foram realizados dois ensaios. $\mathrm{O}$ primeiro comparou o comportamento de SE em ovos com casca íntegra ou com defeitos, armazenados a $30^{\circ} \mathrm{C}$ e a $90 \% \mathrm{UR}$ ou $70 \% \mathrm{UR}$. O segundo comparou o comportamento de SE em ovos de casca íntegra, lavados industrialmente ou não, sob as mesmas condições de temperatura e de UR. Os procedimentos de conservação e a forma de contaminação dos ovos foram idênticos para os dois ensaios. A lavagem industrial foi realizada em lavador Yamasa, modelo ECB9680, com água não clorada a $55^{\circ} \mathrm{C}$ (medida na saída dos bicos ejetores). Após a secagem, os ovos foram colhidos na esteira e dispostos em bandejas plásticas de transporte.

A contaminação dos ovos foi feita pelo contato de sua região equatorial com fezes frescas das aves doadoras dos ovos, inicialmente esterilizadas por calor úmido $\left(121^{\circ} \mathrm{C} / 10 \mathrm{~min}\right)$, resfriadas à temperatura ambiente $\mathrm{e}$, posteriormente, contaminadas com cepa de SE, isolada da produção avícola e resistente ao ácido nalidíxido (SE $\mathrm{NAL}^{\mathrm{R}}$ ). Obteve-se a contaminação média de 2,0 $\log _{10} \mathrm{UFC} /$ unidade amostral e de 6,0 $\log _{10} \mathrm{UFC} / \mathrm{g}$ de fezes. Após a contaminação, os ovos foram dispostos em bandeja plástica e secos em temperatura ambiente por 60 minutos e, então, submetidos às condições de armazenagem de refrigeração $-8^{\circ} \mathrm{C}$ e $70 \% \pm 5 \%$ UR e excessiva $-30^{\circ} \mathrm{C}$ e $90 \pm 5 \%$ UR .

A cada tempo definido previamente, 0, 24, 48, 72, 168 e 336 horas, foram analisadas cinco unidades amostrais. A recuperação dos microrganismos da casca foi realizada por lavagem da superfície dos ovos, com metodologia adaptada de Gentry e Quarles

${ }^{1}$ Disponível em http://www.defra.gov.uk/foodrin/poultry/pdfs/ eggqual.pdf. 
(1972), por Pinto (2005), com água peptonada tamponada (APT) sendo esta recolhida, considerada a diluição $10^{\circ}$, em tubos de vidro estéreis com tampa-rosca e incubada a $35-37^{\circ} \mathrm{C}$ por 24 horas, como enriquecimento. A contagem de SE foi realizada conforme metodologia descrita por Silva et al. (2001), a partir de diluições decimais sucessivas das amostras e plaqueamento de $0,1 \mathrm{~mL}$ na superfície de placas de Petri contendo ágar MacConkey adicionado de $100 \mu \mathrm{g} / \mathrm{mL}$ de ácido nalidíxico e novobiocina. As placas foram incubadas por $24-48 \mathrm{~h}$ a $37^{\circ} \mathrm{C}$. Após o período de incubação, realizou-se a contagem das colônias. A confirmação bioquímica das colônias encontradas seguiu as recomendações de Silva et al. (2001). Devido ao pequeno número de microrganismos esperado, foi plaqueado, também, $1,0 \mathrm{~mL}$ da primeira diluição, sendo três placas com $0,3 \mathrm{~mL}$ e uma placa com $0,1 \mathrm{~mL}$ (em triplicata). A primeira diluição foi incubada a $35-37^{\circ} \mathrm{C}$ por 24 horas, como enriquecimento, para verificar a presença do microrganismo. Os ovos submetidos à lavagem da casca foram drenados e imersos em álcool etílico $70 \%$ por aproximadamente 40 minutos, drenados e flambados. Albúmem e gema, obtidos assepticamente, foram separados e transferidos para sacos plásticos estéreis, pesados e adicionados de APT a fim de obter a diluição $10^{-1}$. As amostras foram homogeneizadas em homogeneizador de pistões (20 segundos) e incubadas a $35-37^{\circ} \mathrm{C}$ por 24 horas, para verificar a presença de $\mathrm{SE}$.

Os resultados obtidos das análises microbiológicas - as contagens foram transformadas em $\log 10$ - foram submetidos à análise de variância $(\alpha=0,05)$ e ao teste Tukey a fim de verificar a influência das diferentes classificações/tratamento de ovos e o tipo de armazenagem, ao longo do tempo, sobre a contagem bacteriana na casca (Montgomery, 1997). Os dois ensaios foram analisados separadamente. Dados referentes à presença do microrganismo na superfície dos ovos não foram analisados estatisticamente e foram apresentados nos resultados apenas para ilustração. Os referentes à presença do microrganismo no albúmem e na gema foram submetidos ao teste de Fisher, a partir da categorização binária dos dados (presença e ausência), segundo Fleiss (1981), pois a obtenção de contagem foi mínima e a presença de SE no conteúdo interno foi identificada em poucas unidades amostrais.
Ao longo do período experimental, foi mensurada a gravidade específica dos ovos produzidos pelo lote das aves doadoras, utilizando-se a metodologia descrita por Hamilton (1982). A medida da gravidade específica foi realizada na granja, a cada coleta de amostras para os ensaios, com 100 unidades amostrais colhidas aleatoriamente.

\section{RESULTADOS E DISCUSSÃO}

A gravidade específica média dos ovos submetidos à contaminação foi de 1090,36g/L, sendo os extremos 1091,0 e $1089,6 \mathrm{~g} / \mathrm{L}$. Foram considerados de excelente qualidade segundo classificação de Sauter e Petersen (1974).

Na Tab. 1, apresenta-se o comportamento de SE na casca de ovos com casca íntegra e com defeitos, ao longo do tempo e nas condições de armazenagem estudadas. O comportamento do microrganismo variou, ao longo do tempo $(\mathrm{P}<0,01)$ na superfície dos ovos quando comparados à qualidade da casca e às condições de armazenagem. Nos ovos com casca íntegra, mantidos a $30^{\circ} \mathrm{C}$ e $90 \pm 5 \% \mathrm{UR}$, a presença de SE diminuiu com o tempo, sendo detectada somente até a $72^{\mathrm{a}}$ hora de armazenagem, enquanto em ovos refrigerados, mantidos a $8^{\circ} \mathrm{C}$ e $70 \pm 5 \% \mathrm{UR}$, a quantidade de SE na casca manteve-se estável até o final do período de análise de 336 horas. Estas observações assemelham-se às de Oliveira e Silva (2000). O fato de a refrigeração favorecer a sobrevivência de SE na casca, em detrimento da armazenagem a $30^{\circ} \mathrm{C}$, deve-se à maior fragilidade/atividade desse microrganismo nesta temperatura, aliada às precárias condições de suporte nutricional.

O comportamento de SE em ovos com casca defeituosa teve perfil semelhante. Nesta condição de qualidade de casca, o microrganismo permaneceu viável por mais tempo e em maior quantidade, principalmente a $30^{\circ} \mathrm{C}$ e $90 \pm 5 \% \mathrm{UR}$. Os dados sugerem que a presença de salmonela na casca de ovos é dependente do tempo/temperatura de armazenagem e da qualidade da casca, como observado por Radkowski (2002). Entretanto, a $8^{\circ} \mathrm{C}$ e $70 \%$ UR, a qualidade da casca não determinou a sobrevivência do microrganismo $(\mathrm{P}>0,01)$. 
Ensaios de penetração de Salmonella Enteritidis...

Tabela 1. Contagem de Salmonella Enteritidis ( $\log _{10}$ UFC/unidade amostral) em casca de ovos íntegros ou com defeitos de casca, contaminados via fezes e submetidos a diferentes condições de armazenagem

\begin{tabular}{|c|c|c|c|c|c|c|c|c|}
\hline \multirow{2}{*}{$\begin{array}{l}\text { Tempo de } \\
\text { armazenagem }\end{array}$} & \multicolumn{4}{|c|}{ Ovos com casca íntegra } & \multicolumn{4}{|c|}{ Ovos com casca defeituosa } \\
\hline & & $30^{\circ} \mathrm{C} 90 \% \mathrm{UR}$ & & $8^{\circ} \mathrm{C} 70 \% \mathrm{UR}$ & & $30^{\circ} \mathrm{C} 90 \pm 5 \%$ & & $8^{\circ} \mathrm{C} 70 \% \mathrm{UR}$ \\
\hline (h) & $\mathrm{N}$ & $\mathrm{M} \pm \mathrm{DP}$ & $\mathrm{N}$ & $\mathrm{M} \pm \mathrm{DP}$ & $\mathrm{N}$ & $\mathrm{M} \pm \mathrm{DP}$ & $\mathrm{N}$ & $\mathrm{M} \pm \mathrm{DP}$ \\
\hline 0 & 5 & $2,25 \pm 0,367$ & 5 & $2,25 \pm 0,367$ & 5 & $2,44 \pm 0,587$ & 5 & $2,44 \pm 0,587$ \\
\hline 24 & 5 & $0,65 \pm 0,516$ & 5 & $2,85 \pm 0,127$ & 5 & $1,64 \pm 1,618$ & 5 & $3,66 \pm 0,585$ \\
\hline 48 & 5 & $0,98 \pm 0,828$ & 5 & $2,78 \pm 0,446$ & 5 & $2,51 \pm 1,933$ & 5 & $3,45 \pm 0,526$ \\
\hline 72 & $5^{*}$ & - & 5 & $2,49 \pm 0,572$ & 4 & $0,17 \pm 0,150$ & 5 & $2,68 \pm 0,622$ \\
\hline 168 & 0 & ND & 5 & $2,34 \pm 0,752$ & 2 & $3,77 \pm 0,116$ & 5 & $2,26 \pm 1,076$ \\
\hline 336 & 0 & ND & 5 & $2,07 \pm 0,636$ & $2 *$ & - & 5 & $1,66 \pm 1,029$ \\
\hline Média** & 20 & $1,10 \pm 0,935 \mathrm{~b}$ & 30 & $2,46 \pm 0,554 \mathrm{ab}$ & 23 & $2,04 \pm 1,514 \mathrm{~b}$ & 30 & $2,69 \pm 0,990$ c \\
\hline
\end{tabular}

$\mathrm{N}$ : número de unidades amostrais com crescimento; UR: umidade relativa; ND: não detectado.

$\mathrm{M} \pm$ DP: Média ( $\log _{10}$ UFC/unidade amostral $) \pm$ desvio-padrão.

*crescimento observado após enriquecimento em APT tamponada $\left(35^{\circ} \mathrm{C}\right.$ por $\left.24 \mathrm{~h}\right)$.

$* *$ Valores de contagem, na linha, seguidos de letras diferentes diferem entre si para $\alpha=0,05$.

A invasão do conteúdo dos ovos por SE ocorreu apenas em ovos com casca defeituosa e armazenados sob temperatura de $30^{\circ} \mathrm{C}$ (em três albúmem e uma gema, na $48^{\mathrm{a}}$ hora de armazenagem). Esta ocorrência teve significância estatística $(\mathrm{P}<0,05)$, comprovando que ovos com casca defeituosa, quando submetidos a altas temperaturas, podem ter seu conteúdo invadido por SE. SE não foi encontrada no conteúdo de ovos refrigerados.

Está bem demonstrado que a intensidade de penetração é dependente, também, da carga contaminante inicial. O uso de inóculos de até $4,0 \quad \log _{10}$ UFC/ovo pode não propiciar a penetração, mesmo após 21 dias de armazenagem (Radkowski, 2002). Entretanto, quando se usa inóculos maiores, 5,0 $\log _{10}$ UFC/ovo, em ovos de casca íntegra, encontra-se o microrganismo no conteúdo já nas primeiras 24 horas após a inoculação (Oliveira e Silva, 2000), indicando maior taxa de penetração para o conteúdo de ovos (Chen et al., 1996; Miyamoto et al., 1998; Braun et al., 1999, citado por Messens et al., 2005). Não existem relatos sobre quantidade de salmonela contaminando naturalmente a superfície de ovos de galinha, porém estudos demonstram que ovos frescos podem apresentar em sua superfície de 3,0 a 5,0 $\log _{10}$ UFC/unidade de bactérias mesófilas (Gentry e Quarles, 1972). Este estudo sugere que a armazenagem de ovos com casca defeituosa sob temperatura de $30^{\circ} \mathrm{C}$, contaminados por salmonelas, constitui risco à contaminação de seu conteúdo, uma vez que nesta temperatura houve penetração e multiplicação do microrganismo no conteúdo de ovos cuja casca foi contaminada com SE $(\mathrm{P}<0,05)$. Wang e Slavik (1998) não encontraram nenhuma diferença na penetração de SE em ovos de casca íntegra, mas demonstraram que o índice de penetração a $23^{\circ} \mathrm{C}$ é levemente mais alto que a $4^{\circ} \mathrm{C}$. Além disso, a velocidade de penetração é maior a $23^{\circ} \mathrm{C}$ que a $4{ }^{\circ} \mathrm{C}-30 \%$ a $23^{\circ} \mathrm{C}$ e $20 \%$ a $4^{\circ} \mathrm{C}$ - no sétimo dia de incubação. Radkowski (2002) não encontrou relação entre temperatura de armazenagem e penetração de SE em ovos íntegros.

Os estudos de Sauter e Petersen (1974) comprovaram que ovos com excelente qualidade de casca são consideravelmente mais resistentes à penetração dos diversos sorotipos de Salmonella do que ovos com cascas de baixa qualidade. De Reu et al. (2004) verificaram que $35 \%$ dos ovos contaminados e armazenados a $20^{\circ} \mathrm{C}$ tiveram seu conteúdo invadido, enquanto Sater e Petersen (1974), ao usarem a temperatura de $30^{\circ} \mathrm{C}$, encontraram apenas $10 \%$ de ovos contaminados, quando eles apresentavam excelente qualidade de casca. Não foram encontrados relatos científicos que utilizaram ovos com defeitos de casca.

$O$ fato de não encontrar o microrganismo no conteúdo de ovos com defeitos de casca e armazenados a $30^{\circ} \mathrm{C}$ após a $48^{\mathrm{a}}$ hora de armazenagem confirma os achados de Tranter e Board (1984), que observaram diminuição da contagem ou paralisação de sua multiplicação em albúmem, quando não foi suplementado com ferro ou pela presença de outros componentes com capacidade inibitória da atividade microbiana, em ovos armazenados a $30^{\circ} \mathrm{C}$. 
Gentry e Quarles (1972) acompanharam a viabilidade de microrganismos na casca de ovos armazenados a $4^{\circ} \mathrm{C}$ e $38^{\circ} \mathrm{C}$ e concluíram que a viabilidade diminui ao longo do tempo, principalmente quando os ovos são mantidos em altas temperaturas. Os resultados deste estudo são semelhantes aos encontrados por esses autores.

O comportamento de SE na casca dos ovos lavados e não lavados industrialmente está apresentado na Tab. 2. Ovos de casca íntegra e não lavados apresentaram perfil de contaminação como no ensaio anterior, confirmando a repetibilidade destes resultados. Houve diferença significativa na quantidade de unidades formadoras de colônias do microrganismo, ao longo do tempo $(\mathrm{P}<0,01)$, independentemente de os ovos terem sido lavados ou não. A temperatura de armazenagem foi o fator que determinou a diferença no comportamento do microrganismo na superfície dos ovos, com diminuição de sua contagem a partir das 48 horas de armazenagem a $30^{\circ} \mathrm{C}$ e $90 \%$ UR. A tendência à permanência do microrganismo na superfície de ovos mantidos a $8^{\circ} \mathrm{C}$ coincide com os resultados de Radkowski (2002), que encontrou maior número de ovos com superfície contaminada, quando estes eram mantidos a temperatura de $2^{\circ} \mathrm{C}$ do que a $30^{\circ} \mathrm{C}$. Os ovos mantidos a altas temperaturas tenderam a ter as células bacterianas inviabilizadas, com o passar do tempo. Oliveira e Silva (2000) verificaram a diminuição da carga bacteriana superficial, em até um ciclo logarítmico diariamente, quando os ovos foram mantidos à temperatura ambiente, em torno de $20-25^{\circ} \mathrm{C}$.

Tabela 2. Contagem de Salmonella Enteritidis ( $\log _{10}$ UFC/unidade amostral) na superfície de ovos de galinha, lavados industrialmente ou não, contaminados via fezes e submetidos a diferentes condições de armazenagem

\begin{tabular}{|c|c|c|c|c|c|c|c|c|}
\hline \multirow{2}{*}{$\begin{array}{c}\text { Tempo de } \\
\text { armazenagem }\end{array}$} & \multicolumn{4}{|c|}{ Ovos com casca íntegra } & \multicolumn{4}{|c|}{ Ovos com casca defeituosa } \\
\hline & & $30^{\circ} \mathrm{C} 90 \% \mathrm{UR}$ & & $8^{\circ} \mathrm{C} 70 \% \mathrm{UR}$ & & $30^{\circ} \mathrm{C} 90 \pm 5 \%$ & & $8^{\circ} \mathrm{C} 70 \% \mathrm{UR}$ \\
\hline (h) & $\mathrm{N}$ & $\mathrm{M} \pm \mathrm{DP}$ & $\mathrm{N}$ & $\mathrm{M} \pm \mathrm{DP}$ & $\mathrm{N}$ & $\mathrm{M} \pm \mathrm{DP}$ & $\mathrm{N}$ & $\mathrm{M} \pm \mathrm{DP}$ \\
\hline 0 & 5 & $2,37 \pm 0,512$ & 5 & $2,37 \pm 0,512$ & 5 & $3,41 \pm 1,215$ & 5 & $3,41 \pm 1,215$ \\
\hline 24 & 5 & $1,80 \pm 1,586$ & 5 & $3,25 \pm 0,451$ & 5 & $1,12 \pm 0,213$ & 5 & $1,92 \pm 0,228$ \\
\hline 48 & 5 & $1,43 \pm 1,008$ & 5 & $2,46 \pm 0,388$ & $2 *$ & - & 5 & $2,04 \pm 0,587$ \\
\hline 72 & 5 & $2,27 \pm 2,259$ & 5 & $2,29 \pm 0,431$ & $1 *$ & - & 5 & $2,15 \pm 0,318$ \\
\hline 168 & $2 *$ & - & 5 & $1,77 \pm 0,443$ & & & 5 & $1,862 \pm 0,381$ \\
\hline & & & & & 0 & ND & & \\
\hline 336 & 0 & ND & 5 & $1,20 \pm 0,341$ & 1 & $1,99 \pm 0$ & 5 & $2,16 \pm 0,236$ \\
\hline Média** & 22 & $1,79 \pm 1,455$ & 30 & $2,22 \pm 0,753$ & 14 & $1,32 \pm 1,734$ & 30 & $2,26 \pm 0,766$ \\
\hline
\end{tabular}

$\mathrm{N}$ : número de unidades amostrais com crescimento; UR: umidade relativa; ND: não detectado.

$\mathrm{M} \pm \mathrm{DP}:$ Média ( $\log _{10}$ UFC/unidade amostral) \pm desvio-padrão.

*crescimento observado após enriquecimento em ATP tamponada $\left(35^{\circ} \mathrm{C}\right.$ por $\left.24 \mathrm{~h}\right)$.

**média geral, por coluna.

Aparentemente, existe a possibilidade de recuperar células de SE por mais tempo em casca de ovos lavados e submetidos a altas temperaturas do que de ovos não lavados, também mantidos em temperaturas altas. Este resultado pode ser justificado pela diminuição da microbiota normal da superfície do ovo pela lavagem correta, o que diminuiria a competição, favorecendo a permanência dos microrganismos inoculados (Moats, 1979; Moats, 1981).

Deve-se considerar, também, que a lavagem industrial estaria removendo a cutícula e, consequentemente, retirando seus fatores antiaderentes naturalmente presentes (Berrang et al., 1999).

A lavagem industrial de ovos é prática aceitável, sob ponto de vista higiênico-sanitário, desde que atendidos os requisitos de temperatura $\mathrm{e}$ qualidade da água. Ela é obrigatória em alguns países (Hutchison et al., 2003). Deve-se, entretanto, evitar a recontaminação das cascas após os procedimentos de higienização. A contagem de SE em ovos não lavados na $72^{\mathrm{a}}$ hora de armazenagem, sob temperatura de $30^{\circ} \mathrm{C}$, foi maior que as encontradas nos tempos anteriores. Esse fato deve-se à dificuldade de manter quantidade sempre padronizada de 
contaminação da casca e não à multiplicação do microrganismo. $\mathrm{O}$ resultado deve ser visto como a manutenção de $\mathrm{SE}$ nos mesmos níveis anteriores. Além disso, a análise estatística não revelou diferença neste resultado em relação aos demais $(\mathrm{P}<0,05)$. Ocorreu a invasão por $\mathrm{SE}$ em apenas uma unidade amostral, não lavada e armazenada a $30^{\circ} \mathrm{C}$ na $72^{\mathrm{a}}$ hora de armazenagem. Este achado não foi significativo, entretanto confirma o descrito por Humphrey (1994), que afirma que mesmo ovos de casca íntegra podem ter seu conteúdo invadido por SE, principalmente em temperaturas e umidades altas, como foi o caso. Após 72 horas de armazenagem, o microrganismo não foi mais isolado. Tranter e Board (1984) verificaram a diminuição do número de células viáveis de salmonela em albúmem armazenado a $30^{\circ} \mathrm{C}$, provavelmente por causa de suas características antimicrobianas. Não houve invasão para o conteúdo em ovos lavados ou não lavados e submetidos à temperatura de $8^{\circ} \mathrm{C}$. Em ovos submetidos à refrigeração, o índice de invasão de microrganismos para o conteúdo tende a ser menor do que em ovos submetidos a altas temperaturas (Chen et al., 1996; Miyamoto et al., 1998), mas somente quando contaminados com grande número de células bacterianas, o que não ocorreu neste ensaio.

\section{CONCLUSÕES}

Em ovos contaminados por salmonelas após a postura, a invasão do conteúdo interno dá-se com mais frequência quando eles são estocados a $30^{\circ} \mathrm{C}$, e menos quando são refrigerados a $8^{\circ} \mathrm{C}$. A viabilidade de salmonelas é maior e de mais longa duração na superfície da casca de ovos quando estes são refrigerados. A lavagem industrial de ovos de consumo deve ser acompanhada de cuidados para evitar a recontaminação do produto. Ovos de consumo deveriam ser comercializados com o menor índice de defeitos de cacas e conservados sob refrigeração, entretanto precisam ser produzidos e estar livres de salmonelas, particularmente na superfície da casca.

\section{REFERÊNCIAS BIBLIOGRÁFICAS}

BERRANG, M.E.; COX, N.A.; FRANK, J.E. et al. Bacterial penetration of the eggshell and shell membranes of the chicken hatching egg: a review. J. Appl. Poult. Res., v.8, p.499-501, 1999.

BOARD, R.G.; TRANTER, H.S. The microbiology of eggs. In: STADELMAN, W.J.; COTTERGIL, O.J. (Eds). Egg science and technology. 4.ed. New York: Haworth Press, 1994. p.81-104.

CARDOSO, A.L.S.P.; TESSARI, E.N.C.; CASTRO, A.G.M. et al. Pesquisa de Salmonella spp. em ovos comerciais, analisados no laboratório de patologia avícola de Descalvado, SP. Rev. Hig. Alim., v.16, p.76-79, 2002.

CHEN, J.; CLARKE, R.C.; GRIFFITHS, M.W. Use of luminescent strains of Salmonella enteritidis to monitor contamination and survival in eggs. J. Food Prot., v.59, p.915-921, 1996.

DAVIES, R.; LIEBANA, E.; BRESLIN, M. Investigation of the distribution and control of Salmonella enterica serovar Enteritidis PT6 in layer breeding and egg production. Avian Pathol., v.32, p.327-337, 2003.

DE REU, K.; GRIJSPEERDT, K.; MESSENS, W. et al. Assessment of the eggshell penetration by different bacteria, including Salmonella Enteritidis, isolated from the egg content of consumption eggs. In: WORLD POULTRY CONGRESS, 24., 2004, Istanbul. Anais... Istanbul: WPSA, 2004. (CDROM).

FLEISS, J.L. Statistical methods for rates and proportions. New York: Chichester, 1991. 321p.

GAMA, N.M.S.Q.; BERCHIERI Jr., A.; FERNANDES, S.A. Occurrence of Salmonella sp. in laying hens. Braz. J. Poult. Sci., v.5, p.1521, 2003.

GENTRY, R.F.; QUARLES, C.L. The measurement of bacterial contamination on egg shells. Poult. Sci., v.51, p.930-933, 1972.

HAMILTON, R.M.G. Methods and factors that affect the measurement of egg shell quality. Poult. Sci., v.61, p.2022-2039, 1982.

HENZLER, D.J.; KRADEL, D.C.; SISCHO, W.M. Management and environmental risk factors for Salmonella enteritidis contamination of eggs. Am. J. Vet. Res., v.59, p.824-829, 1998.

HENZLER, D.J.; OPITZ, H.M. The role of mice in the epizootiology of Salmonella enteritidis infection on chicken layer farms. Avian Dis., v.36, p.625-631, 1992. 
HUMPHREY, T.J. Contamination of eggshell and contents with Salmonella enteritidis: a review. Int. J. Food Microbiol., v.21, p.31-40, 1994.

HUTCHISON, M.L.; GITTINS, J.; WALKER, A. et al. Washing table eggs: a review of the scientific and engineering issues. World's Poult. Sci. J., v.59, p233-248, 2003.

LATIMER, H.K.; JAYKUS, L.A.; MORALES, R.A. et al. Sensitivity analysis of Salmonella enteritidis levels in contaminated shell eggs using a biphasic growth model. Int. J. Food Microbiol., v.75, p.71-87, 2000.

MESSENS, W.; GRIJSPEERDT, K.; HERMAN, L. Eggshell penetration by Salmonella: a review. World's Poult. Sci. J., v.61, p.71-85, 2005.

MIYAMOTO, T.; HORIE, T.; BABA, E. et al. Salmonella penetration through eggshell associated with freshness of laid eggs and refrigeration. J. Food Prot., v.61, p.350-353, 1998.

MOATS, W.A. The effect of washing eggs under commercial conditions on bacterial loads on egg shells. Poult. Sci., v.58, p.1228-1233, 1979.

MOATS, W.A. Factors affecting bacterial loads on shells of commercially washed eggs. Poult. Sci., v.60, p.2084-2090, 1981

MONTGOMERY, D.C. Design and analysis of experiments. 4.ed. New York: Wiley, 1997. 704p.

OLIVEIRA, D.D.; SILVA, E.N. Salmonella em ovos comerciais: ocorrência, condições de armazenamento e desinfecção da casca. Arq. Bras. Med. Vet. Zootec., v.52, p.655-661, 2000.

PERESI, J.T.M.; ALMEIDA, I.A.Z.C.; LIMA, S.I. et al. Surtos de enfermidades transmitidas por alimentos causados por Salmonella Enteritidis. Rev. Saúde Pública, v.32, p.477-483, 1998.

PINTO, A. T. Estudo do comportamento de Salmonella Enteritidis e Escherichia coli na casca, sua penetração no conteúdo interno $e$ alterações na qualidade em ovos de galinha contaminados artificialmente simulando condições usuais de produção comercial. 2005. 164f. Tese (Doutorado) - Faculdade de Engenharia de Alimentos, Universidade Estadual de Campinas. Campinas, SP.

RADKOWSKI, M. Effect of moisture and temperature on survival of Salmonella Enteritidis on shell eggs. Arch. Geflügelk., v.66, p.119-123, 2002.

SAUTER, E.A.; PETERSEN, C.F. The effect of egg shell quality on penetration by various Salmonellae. Poult. Sci., v.53, p.2159-2162, 1974.

SILVA, E.N.; BOSQUIROLI, S.L. Epidemiological occurrence of Salmonella in a broiler integrated company. In: WORLD POULTRY CONGRESS, 22., 1996, New Delhi. Proceedings... New Delhi: WPSA, 1996. (Abstract).

SILVA, N.; JUNQUEIRA, V.C.A.; SILVEIRA, N.F.A. Manual de métodos de análise microbiológica de alimentos. 2.ed. São Paulo:Varela. 2001.317p.

SOLOMON, S.E. Egg and eggshell quality. London: Wolfe, 1991. 149p.

SUMMERS, J. How much do eggs contribute to the Salmonella problem. Disponível em: < http://www.poultryindustrycouncil.ca/factsheets/fs_6 1.pdf > . Acessado em 12 jan. 2002.

TAVECHIO, A.T.; GHILARDI, A.C.R.; PERESI, J.T.M. et al. Salmonella serotypes isolated from nonhuman sources in São Paulo, Brazil, from 1996 through 2000. J. Food Prot., v.65, p.1041-1044, 2002.

TRANTER, H.S.; BOARD, R.G. The influence of incubation temperature and $\mathrm{pH}$ on the antimicrobial properties of hen egg albumen. J. Appl. Microbiol., v.56, p.53-61, 1984.

TOOD, E.C.D. Risk assessment of use of cracked eggs in Canada. Int. J. Food Microbiol., v.30, p.125143, 1996.

WANG, H.; SLAVIK, M.F. Bacterial penetration into eggs washed with various chemicals and stored at different temperatures and times. J. Food Prot., v.61, p.276-279, 1998. 